Pacific Journal of Mathematic 


\title{
ON SOME TYPES OF COMPLETENESS IN TOPOLOGICAL VECTOR SPACES
}

\author{
J. A. Marti
}

A type of closed family is defined for which problems of existence, construction and approximation are examined in some topological vector spaces or their conjugate spaces.

\section{Definition of a type of completeness.}

1.1. Let $E$ denote a real or complex topological vector space, $E^{\prime}$ its conjugate space, $I$ a set of indices (occasionally $I=N$ ), $\left(x_{i}\right)_{i \in I}$ a family of elements in $E, V$ the vector space of families $\lambda=\left(\lambda_{i}\right)_{i \in I}$ of real or complex numbers, where $\lambda_{i}=0$ except for a finite number of indices, $F$ a semi-norm on $V$. It is recalled that the family $\left(x_{i}\right)_{i \in I}$ is total if the subspace generated by the $x_{i}$ is everywhere dense in $E$, and it is closed (or complete) if $\varphi=0$ is the only $\varphi \in E^{\prime}$ satisfying $\varphi\left(x_{i}\right)=0$ for every $i \in I$. If $E$ is a locally convex space, these definitions are equivalent; then, the existence of a closed sequence is for $E$ a necessary and sufficient condition of separability. New types of completeness have been studied for $I=N$ by $\mathrm{Ph}$. Davis and $\mathrm{Ky}$ Fan [5] in a normed space, and by $\mathrm{S}$. Ja Havinson [6] in a locally convex topological space. The following definitions seem to be more convenient than Havinson's point of view for the generalization to locally convex spaces of some results given by [5].

DEFINITION 1.2. According to precedent notations, we said that the family $\left(x_{i}\right)_{i \in I}$ is $F$-closed in $E$ if:

(C) the conditions $\varphi \in E^{\prime} ;\left|\sum_{i \in I} \lambda_{i} \varphi\left(x_{i}\right)\right| \leqq F(\lambda)$ for all $\lambda=\left(\lambda_{i}\right) \in V$ imply $\varphi=0$.

Clearly a $F$-closed family is a closed family. Let $\left(a_{n}\right)$ be a given sequence of nonnegative numbers, let $p \geqq 1,1 / p+1 / q=1$. Writing $F_{\left(a_{n}\right)}(\lambda)=\sum_{n \in N}\left|\lambda_{n}\right| a_{n} ; F_{p}(\lambda)=\left(\sum_{n \in N}\left|\lambda_{n}\right|^{q}\right)^{1 / q}$ if $p>1 ; F_{p}(\lambda)=$ $\sup _{n \in N}\left|\lambda_{n}\right|$ if $p=1$, for each $\lambda=\left(\lambda_{n}\right) \in V$, we see that definitions of [5] are special cases of the Definition 1.2.

\section{Characteristic property for F-completeness.}

THEOREM 2.1. Let $E$ be a locally convex space. Let $\mathscr{P}=$ $\left(p_{j}\right)_{j \in J}$ be a basis of continuous seminorms on $E$ defining the topology of $E$. The family $\left(x_{i}\right)_{i \in I}$ of elements in $E$ is $F$-closed if and only if: 
(P) For any $x \in E$, for any $p_{j} \in \mathscr{P}$, and for any $\varepsilon>0$, there exists $\lambda=\left(\lambda_{i}\right)_{i \in I} \in V$ such that:

$$
p_{j}\left(x-\sum_{i \in I} \lambda_{i} x_{i}\right)<\varepsilon ; \quad F(\lambda)<\varepsilon .
$$

Proof. "If part". Let $\varphi \in E^{\prime}$ be such that $\left|\sum_{i \in I} \lambda_{i} \varphi\left(x_{i}\right)\right| \leqq$ $F(\lambda)$ for all $\lambda=\left(\lambda_{i}\right) \in V$.

There exist a constant $K>0$ and a seminorm $p_{k}$ such that

$$
|\varphi(y)| \leqq K p_{k}(y) \text { for all } y \in E \text {. }
$$

Given any $x \in E$, there exists $\mu=\left(\mu_{i}\right) \in V$ such that

$$
p_{k}\left(x-\sum_{i \in I} \mu_{i} x_{i}\right)<\varepsilon ; \quad f(\mu)<\varepsilon
$$

We write:

$$
\varphi(x)=\varphi\left(x-\sum_{i \in I} \mu_{i} x_{i}\right)+\sum_{i \in I} \mu_{i} \varphi\left(x_{i}\right)
$$

then:

$$
|\varphi(x)| \leqq(1+K) \varepsilon .
$$

This shows that $\varphi(x)=0$ for all $x \in E$. Hence $\varphi=0$.

"Only if part". Let us put on $V$ the topology defined by the seminorm $F$, and consider the topological product $E \times V$ with its locally convex product topology. Let us denote by $u_{i}=\left(\delta_{i k}\right)_{k \in I}$ the family whose $i$-th term is 1 and all other terms are 0 ; by $\xi_{i}$ the element of $E \times V$ defined by $\xi_{i}=\left(x_{i}, u_{i}\right)$; and by $\mathscr{F}$ the subspace of $E \times V$ spanned by the $\xi_{i}$. The condition (P) of theorem is implied by the following:

(Q) $\left(\forall \varphi \in E^{\prime}\right)\left(\forall \psi \in V^{\prime}\right)\left((\forall i \in I)\left(\varphi\left(x_{i}\right)+\psi\left(u_{i}\right)=0\right) \Rightarrow \varphi=0\right)$ because if $(\mathrm{P})$ is not verified we have:

$(\bar{P}) \quad\left(\exists x_{0} \in E\right)\left(\exists p_{j} \in \mathscr{F}\right)(\exists \varepsilon>0)\left(\forall \lambda=\left(\lambda_{i}\right) \in V\right)\left((\overline{1}) p_{j}\left(x_{0}-\sum_{i \in I} \lambda_{i} x_{i}\right) \geqq\right.$ $\varepsilon$ or $F(\lambda) \geqq \varepsilon)$. The existence of $x_{0}$ implies that $x_{0} \neq 0$ otherwise the two inequalities of ( $\overline{1})$ are contradicted by the choice of $\lambda=0$. Let us denote by $B_{i}$ the "open ball" whose centre is $\left(x_{0}, 0\right)$ which is the product of open balls $b_{i}=\left\{y \in F / p_{j}\left(x_{0}-y\right)<\varepsilon\right\}$ and

$$
\beta=\{v \in V / F(v)<\varepsilon\} .
$$

It is easily seen that there is no element of $\mathscr{F}$ in $B_{i}$, the elements of $\mathscr{F}$ being:

$$
\sum_{i \in I} \lambda_{i} \xi_{i}=\left(\sum_{i \in I} \lambda_{i} x_{i}, \sum_{i \in I} \lambda_{i} u_{i}\right) \text { where } \lambda=\left(\lambda_{i}\right) \in V
$$


because otherwise we should have:

$$
p_{j}\left(x_{0}-\sum_{i \in I} \lambda_{i} x_{i}\right)<\varepsilon ; F\left(\sum_{i \in I} \lambda_{i} u_{i}\right)=F(\lambda)<\varepsilon
$$

and that is in contradiction with the two inequalities of $(\overline{1})$.

Then $\left(x_{0}, 0\right)$ is the centre of an open "ball" which contains no element of $\mathscr{F}$ and $\left(x_{0}, 0\right) \in E \times V-\overline{\mathscr{F}}$. And then there exists a linear continuous functional $\Phi$ on $E \times V$ such that $\Phi\left(x_{0}, 0\right) \neq 0$ and vanishing on $\overline{\mathscr{F}}$ and $\mathscr{F}$ (cf., e.g., [8, Th. 3.8. E]).

Now $\Phi$ is written in unique way: (cf., e.g., [4, Ch. IV])

$$
\Phi:(x, v) \longrightarrow \varphi(x)+\psi(v) \text { where } \varphi \in E^{\prime}, \psi \in V^{\prime},
$$

and we have:

$$
\varphi\left(x_{0}\right)=\Phi\left(x_{0}, 0\right) \neq 0 .
$$

Then $\varphi \neq 0$, and that involves:

$$
(\bar{Q})\left(\exists \varphi \in E^{\prime}\right)\left(\exists \psi \in V^{\prime}\right)\left((\forall i \in I)\left(\varphi\left(x_{i}\right)+\psi\left(u_{i}\right)=0\right) \text { and } \varphi \neq 0\right) .
$$

The implication $(\bar{P}) \Longrightarrow(\bar{Q})$ is proved, i.e., the implication $(Q) \Rightarrow(P)$.

It only remains to prove that condition (C) implies $(Q)$. For a given $\varphi \in E^{\prime}$, if there exists $\psi \in V^{\prime}$ such that for all $i \in I$

$$
\varphi\left(x_{i}\right)+\psi\left(u_{i}\right)=0
$$

we have, for all $\lambda=\left(\lambda_{i}\right) \in V$ :

$$
\left|\sum_{i \in I} \lambda_{i} \varphi\left(x_{i}\right)\right|=\left|\sum_{i \in I} \lambda_{i} \psi\left(u_{i}\right)\right|=\left|\psi\left(\sum_{i \in I} \lambda_{i} u_{i}\right)\right|=|\psi(\lambda)| \leqq\|\psi\| F(\lambda)
$$

where \|\| is the usual norm on $V^{\prime}$. Hence $\varphi=0$.

REMARKS 2.2. It is easily seen that for any semi norm $F$ on $V$ a $F$-closed family is total because the first of inequalities (1) of Theorem 2.1 proves that the subspace generated by $\left(x_{i}\right)$ is everywhere dense in $E$. Then taking $F=0$ we have: In a locally convex space a closed family is total. The converse is easily proved and we find again the equivalence of these two properties. If $E$ is a normed space, the Theorem 2.1 has as corollaries Theorems 1 and 2 of [5]; moreover it extends them in the case of families in locally convex spaces. At last it results of the demonstration that the condition (Q) is also necessary and sufficient for the family $\left(x_{i}\right)$ to be $F$-closed. We shall make use of this result at $\S 6$. 
3. F-closed families in the conjugate of a locally convex Hausdorff space.

Proposition 3.1. Let $E$ be a locally convex Hausdorff semireflexive space. A family $\left(L_{i}\right)_{i \in I}$ of elements in $E^{\prime}$ is $F$-closed for the strong topology of $E^{\prime}$ if and only if the conditions:

$$
x \in E ;\left|\sum_{i \varepsilon I} \lambda_{i} L_{i}(x)\right| \leqq F(\lambda) \text { for all } \lambda=\left(\lambda_{i}\right) \in V
$$

imply $x=0$.

We do not give the proof which results from the fact that $E$ being semi-reflexive, and $\varphi \in E^{\prime \prime}$ (second conjugate of $E$ ) is written

$$
\varphi: L \longrightarrow L(x) \text { where } x \in E,
$$

for each $L \in E^{\prime}$, and that, by Hahn-Banach, $x=0$ is the only $x \in E$ for which $L(x)=0$ for all $L \in E^{\prime \prime}$.

EXAMPLES 3.2. We denote by $\mathscr{H}(\Omega)$ the space of holomorphic functions is the unit disc, with the topology of compact convergence. Let $\left(z_{n}\right)_{n \in N}$ be a sequence of complex numbers such that $0<\left|z_{n}\right|<1$, $\lim _{n \rightarrow \infty} z_{n}=0$. We denote by $\left(L_{n}\right)_{n \in N}$ the sequence of elements in [ $\mathscr{H}(\Omega)]^{\prime}$ defined by $L_{n}(f)=f\left(z_{n}\right)$ for all $n \in N$ and all $f \in \mathscr{H}(\Omega)$. Let $F$ be a semi norm on $V$ :

3.2.1. If $\lim _{n \rightarrow \infty}\left(F\left(u_{n}\right) /\left|z_{n}^{k}\right|\right)=0$ for all $k \in N$ where $u_{n}=\left(\delta_{n m}\right)_{m=0}^{\infty}$, then $\left(L_{n}\right)_{n \in N}$ is $F$-closed for the strong topology of [ $\left.\mathscr{C}(\Omega)\right]^{\prime}$.

3.2.2. If $F=F_{p}$ with $p$ finite (c.f. $\S 1$ ). Then $\left(L_{n}\right)_{n \in N}$ is $F_{p}$-closed for the strong topology of $[\mathscr{H}(\Omega)]^{\prime}$ if and only if the series $\sum_{0}^{\infty}\left|z_{n}\right|^{\alpha}$ diverges for all $\alpha>0$.

4. Construction of F-closed sequences in Fréchet spaces.

Proposition 4.1. Let $\left(x_{n}\right)_{n \in N}$ be a closed sequence of elements in a Fréchet space $\mathscr{F}$, whose topology is defined by an enumerable family of continuous seminorms $\left(p_{i}\right)_{i \in N^{+}}$such that

$$
\sum_{1}^{\infty} 2^{-i} p_{i}\left(x_{n}\right)=A_{n}<+\infty ; \varlimsup \lim A_{n}^{1 / n} \leqq 1
$$

Let $\left(L_{n}\right)_{n \in N}$ be a sequence of elements in [ $\left.\mathscr{C}(\Omega)\right]^{\prime}$ F-closed for the strong topology. Then the sequence $\left(y_{n}\right)_{n \in N}$ of elements in $\mathscr{F}$ associated with $\left(L_{n}\right)$ by 
ON SOME TYPES OF COMPLETENESS IN TOPOLOGICAL VECTOR SPACES 711

$$
y_{n}=\sum_{0}^{\infty} L_{n}\left(\varphi_{k}\right) x_{k}
$$

for all $n \in N$ is F-closed.

Proof. From the continuity of $L_{n} \in[\mathscr{H}(\Omega)]^{\prime}$ we have

$$
\varlimsup_{k \rightarrow \infty}\left|L_{n}\left(\varphi_{k}\right)\right|^{1 / k}<1 .
$$

The topology of $\mathscr{F}$ being equivalent to the metric defined by the distance:

$$
d(x, y)=\sum_{i=1}^{\infty} 2^{-i} \frac{p_{i}(x-y)}{1+p_{i}(x-y)},
$$

we have, with $p(x)=d(x, 0)$ :

$$
\begin{aligned}
p\left[L_{n}\left(\varphi_{k}\right) x_{k}\right] & =\sum_{i=1}^{\infty} 2^{-i} \frac{p_{i}\left[L_{n}\left(\varphi_{k}\right) x_{k}\right]}{1+p_{i}\left[L_{n}\left(\varphi_{k}\right) x_{k}\right]} \leqq\left[L_{n}\left(\varphi_{k}\right)\left|\sum_{i=1}^{\infty} 2^{-i} p_{i}\left(x_{k}\right)\right|\right. \\
& =\left|L_{n}\left(\varphi_{k}\right)\right| A_{k} .
\end{aligned}
$$

Then from (1) we have:

$$
\varlimsup\left[p\left[L_{n}\left(\varphi_{k}\right) x_{k}\right]\right]^{1 / k} \leqq \varlimsup
$$

That proves the convergence of the numerical series $\sum_{0}^{\infty} p\left[L_{n}\left(\varphi_{k}\right) x_{k}\right]$ and as $\mathscr{F}$ is complete, the convergence of the series giving $y_{n}$. Now, let $\varphi \in \mathscr{F}^{\prime}$ be such that, for all $\lambda=\left(\lambda_{n}\right) \in V$ :

$$
\left|\sum_{n \in N} \lambda_{n} \varphi\left(y_{n}\right)\right| \leqq F(\lambda)
$$

The power series $\sum_{0}^{\infty} \varphi\left(x_{k}\right) z^{k}$ has a radius of convergence $R \geqq 1$. Indeed there exists a constant $C$, and an index $i$ such that $|\varphi(x)| \leqq$ $C p_{i}(x)$ for all $x \in \mathscr{F}$, and from (1) we have:

$$
\varlimsup_{n \rightarrow \infty}\left[p_{i}\left(x_{n}\right)\right]^{1 / n} \leqq 1
$$

for each $i \in N^{*}$. Finally

$$
\left.\varlimsup\left|\varphi\left(x_{k}\right)\right|^{1 / k} \leqq \lim C^{1 / k} \varlimsup{ }_{i m}\left(x_{k}\right)\right]^{1 / k} \leqq 1 .
$$

Then the indicated series defines a function holomorphic at least in $\Omega$,

$$
f=\sum_{0}^{\infty} \varphi\left(x_{k}\right) \varphi_{k} \in \mathscr{H}(\Omega) \text { and } L_{n}(f)=\sum_{0}^{\infty} \varphi\left(x_{k}\right) L_{n}\left(\varphi_{k}\right)=\varphi\left(y_{n}\right) .
$$

Then we have: 


$$
\left|\sum_{0}^{\infty} \lambda_{n} L_{n}(f)\right| \leqq F(\lambda) \text { for all } \lambda=\left(\lambda_{n}\right) \in V
$$

As $\left(L_{n}\right)$ is $F$-closed in $[\mathscr{H}(\Omega)]^{\prime}$ that inequality implies $f=0$, from which we gather $\varphi\left(x_{k}\right)=0$ for all $k$ and as $\left(x_{n}\right)$ is closed in $\mathscr{F}: \varphi=0$.

\section{EXAMPLES 4.5 .}

4.5.1. If $\mathscr{F}$ is a Banach space for which $p_{i}(x)=\|x\|$ for every $i$, the precedent condition (1) of $4-1$ is written $\overline{\lim }\left\|x_{n}\right\|^{1 / n} \leqq 1$, and we find again, as a corollary, the Theorem 3 of [5].

4.5.2. Let $\left(a_{n}\right)_{n \in N}$ be a given sequence of numbers $\geqq 0,\left(z_{n}\right)_{n \in N}$ a sequence of complex numbers such that, $K$ being a constant $\geqq 0$; $a_{n}^{1 / n} \leqq K\left|z_{n}\right| ; 0<\left|z_{n}\right|<1 ; \lim z_{n}=0$. Let $g=\sum_{0}^{\infty} \alpha_{k} \varphi_{k} \in \mathscr{H}(\Omega)$ with $\alpha_{k} \neq 0$ for all $k$. Then, the sequence $\left(y_{n}\right)$ of elements in $\mathscr{H}(\Omega)$ defined by $y_{n}(z)=g\left(z z_{n}\right)$ for all $z \in \Omega$ is $F_{\left(a_{n}\right)}$-closed.

5. Existence of semi norms associated to a given family. For a given family $\left(x_{i}\right)_{i \in I}$ of elements in $E$ when does one know whether there exists a semi norm $F$ such that $\left(x_{i}\right)$ is $F$-closed?

DEFINITION 5.1. On the space $V$ we defined the order relation (not total) $\leqq$ by: $\lambda^{\prime} \leqq \lambda$ if every term $\neq 0$ in $\lambda^{\prime}$ is a term in $\lambda$ with the same index. We shall denote $F^{*}$ any semi norm increasing on $V$.

THEOREM 5.2. Let us suppose $\left(x_{i}\right)_{i \in I}$ to be topologically free ([4], Ch. I]). If $\left(x_{i}\right)_{i \in I}$ is $F^{*}$-closed, then $F^{*}=0$.

Proof. Let $u_{i}=\left(\delta_{j k}\right)_{k \in I} \in V$. If $F^{*}=0$ there exists $j \in I$ such that $F^{*}\left(u_{j}\right) \neq 0$. Let $E_{j}$ be the subspace spanned by the elements of $\left(x_{i}\right)$ other than $x_{j}$. Then by Hahn-Banach, there exists $\varphi \in E^{\prime}$ such that $\varphi\left(\bar{E}_{j}\right)=0$ and $\varphi\left(x_{j}\right)=1$. Let us write $\psi=F^{*}\left(u_{j}\right) \varphi: \psi$ does not vanish, and that is in contradiction, if $\left(x_{i}\right)$ is $F^{*}$-closed, with

$$
\left|\sum_{i \in I} \lambda_{i} \psi\left(x_{i}\right)\right|=\left|\lambda_{j}\right| F^{*}\left(u_{j}\right)=F^{*}\left(\lambda_{j} u_{j}\right) \leqq F^{*}\left(\sum_{i \in I} \lambda_{i} u_{i}\right)=F^{*}(\lambda)
$$

for all $\lambda=\left(\lambda_{i}\right) \in V$.

COROLlaRY 5.3. In a topological vector space (resp. metrizable and complete) any Schauder basis (resp. any basis) is $F^{*}$-closed if and only if $F^{*}=0$. 
semi reflexive space (resp. Eréchet semi reflexive space) the sequence of the coefficient functionals associated with any Schauder basis (resp. any basis) is strongly $F^{*}$-closed if and only if $F^{*}=0$. (See, e.g., [2, Ch. VII, §3], [7, p. 431-432], [1, Th. 2]).

EXAMPLE 5.5. The sequence $\left(\varphi_{n}\right)_{n \in N} \varphi_{n}: z \rightarrow z^{n}$ is a Schauder basis for $\mathscr{H}(\Omega)$. Then it is $F^{*}$-closed (e.g., $F^{*}=F_{\left(a_{n}\right)}$ or $F^{*}=F_{p}$ ) if and only if $F^{*}=0$. From 5.4 we have the same results with the sequence of the coefficient functionals in $[\mathscr{H}(\Omega)]^{\prime}:\left(L_{n}\right)_{n \in N}$ such that $L_{n}(f)=\left(f^{(n)}(0) / n !\right)$ for all $f \in \mathscr{H}(\Omega)$ and also from 5.3 because $\mathscr{H}(\Omega)$ being reflexive, $\left(L_{n}\right)$ is a strong Schauder basis for $[\mathscr{H}(\Omega)]^{\prime}$.

6. Neighboring F-closed families in Paley-Wiener sense. (On the Paley-Wiener theorem see, e.g., [3, Th. 1.1]; [5, Th. 4]; [1]). We shall prove that $F$-completeness of a family $\left(x_{i}\right)$ is carried into another family $\left(y_{i}\right)$ closed to $\left(x_{i}\right)$ in the sense of the following:

THeOREM 6.1. Let $E$ be a locally convex space. Let $\mathscr{P}=\left(p_{j}\right)_{j \in J}$ $a$ basis of continuous seminorms on $E$ defining the topology of $E$. Let $\left(x_{i}\right)_{i \in I}$ and $\left(y_{i}\right)_{i \in I}$ be two families of elements in $E$. Let us suppose that there exists a family $\left(k_{j}\right)_{j \in J}$ of real numbers $\left(0 \leqq k_{j}<1\right)$ such that, for all $\lambda \in\left(\lambda_{i}\right) \in V$ :

$$
p_{j}\left(\sum_{i \in I} \lambda_{i}\left(x_{i}-y_{i}\right)\right) \leqq k_{j} p_{j}\left(\sum_{i \in I} \lambda_{i} x_{i}\right)
$$

for every $j \in J$. Then, if $\left(x_{i}\right)$ is F-closed, so is $\left(y_{i}\right)$.

Proof. The notations are those of Theorem 2.1. According to Remarks 2.2, to prove that $\left(y_{i}\right)$ is $F$-closed we must show that the conditions:

$$
\varphi \in E^{\prime}, \psi \in V^{\prime} \varphi\left(y_{i}\right)+\psi\left(U_{i}\right)=0
$$

for all $i \in I$ imply $\varphi=0$.

Then, Let $\varphi$ and $\psi$ be such that the conditions (2) are verified, and let

$$
\alpha_{i}=\varphi\left(x_{i}\right)+\psi\left(U_{i}\right)=\varphi\left(x_{i}-y_{i}\right) .
$$

There exist a constant $K>0$ and an index $j \in I$ such that:

$$
|\varphi(x)| \leqq K p_{j}(x) \text { for all } x \in E,
$$

and as $\|\varphi\|_{j}=\inf \left\{H /(\forall x \in E) \varphi(x) \leqq H p_{j}(x)\right\}$ is a norm on $E^{\prime}$, we also have:

$$
|\varphi(x)| \leqq\|\varphi\|_{j} p_{j}(x) \text { for all } x \in E
$$


Then, from (1), for all $\lambda=\left(\lambda_{i}\right) \in V$ :

$$
\left|\sum_{i \in I} \lambda_{i} \alpha_{i}\right| \leqq\|\varphi\|_{j} p_{j}\left(\sum_{i \in I} \lambda_{i}\left(x_{i}-y_{i}\right)\right) \leqq k_{j}\|\varphi\|_{j} p_{j}\left(\sum_{i \in I} \lambda_{i} x_{i}\right) .
$$

By the generalization of Banach's result ([2, Ch. IV, §3, Th. 5]), this proves the existence of $\varphi_{1} \in E_{\tau_{j}}^{\prime}$ (that is to say a linear functional on $E$ continuous for the semi norm $p_{j}$ topology and consequently, for the initial topology of $E$ ) such that:

$$
\left\|\varphi_{1}\right\|_{j} \leqq k_{j}\|\varphi\|_{j} \text { and } \varphi_{1}\left(x_{i}\right)=\alpha_{i}
$$

for all $i \in I$. Then we have:

$$
\left(\varphi-\varphi_{1}\right)\left(x_{i}\right)+\psi\left(v_{i}\right)=0 \text { for all } i \in I \text {. }
$$

As $\varphi_{1} \in E^{\prime}$ and $\varphi-\varphi_{1} \in E^{\prime}$, according to $F$-completeness of $\left(x_{i}\right)$ we have, from (2) $\varphi-\varphi_{1}=0$. Then $\|\varphi\|_{j} \leqq k_{j}\|\varphi\|_{j}$ with $0 \leqq k_{i}<1$. Hence $\varphi=0$.

COROLlaRY 6.2. If $\left(x_{i}\right)$ and $\left(y_{i}\right)$ satisfy the hypothesis of Theorem 6.1 with $0 \leqq k_{i} \leqq 1 / 2$ for all $i \in I$, then these families are simultaneously F-closed or not.

Corollary 6.3. Let $E$ be a Fréchet space, of which the topology is defined by an enumerable family of continuous norms $\left(\|\|_{i}\right)_{i \in N^{*}}$. Let us suppose that $E$ is a unitary normed algebra for each \|\|$_{i}$. Let $\left(x_{n}\right)_{n \in N}$ be an absolutely convergent basis in $E$, and $\left(\varepsilon_{n}\right)_{n \in N}$ be a sequence of elements in $E$ :

$$
\varepsilon_{n}=\sum_{k=0}^{\infty} \varphi_{k}\left(\varepsilon_{n}\right) x_{k},
$$

such that

$$
\sum_{k=0}^{\infty}\left\|\varphi_{k}\left(\varepsilon_{n}\right) x_{k}\right\|_{i} \leqq l
$$

(a given constant) for every $i \in N^{*}$. Let $\left(y_{n}\right)_{n \in N}$ be the sequence of elements in $E$ defined by

$$
y_{n}=x_{n}\left(1+\varepsilon_{n}\right)
$$

for every $n \in N$. Then

(i) If $l<1$ and if there exists a semi norm $F$ on $V$ such that $\left(x_{n}\right)$ is F-closed, so is $\left(y_{n}\right)$.

(ii) If $l<1 / 2,\left(x_{n}\right)$ and $\left(y_{n}\right)$ are simultaneously $F$-closed or not. Particularly $\left(y_{n}\right)$ is $F^{*}$-closed if and only if $F^{*}=0$. 


\section{BIBLIOGRAPHY}

1. M. C. Arsove, The Paley-Wiener theorem in metric linear spaces, Pacific J. Math. 10 (1960).

2. S. Banach, Theories des Opérations Linéaires, Chelsea Publishing Company, New York, 1955.

3. R. P. Boas Jr, Expansion theorems for analytic functions, Conférence on functions of a complex variable, University of Michigan, 1953, 409-419.

4. N. Bourbaki, Espaces vectoriels topologiques, Ch. I-V, Hermann 1964.

5. Ph. Davis and K. Fan, Complete sequences and approximation in normed linear spaces, Duke Math. J. 24 (1957), 183-192.

6. S. Ja Havinson, Some problems concerning the completeness of systems, Dokl. Akad. Nauk. SSSR. 137 (1961), 793-798; MR 23, A 1044.

7. W. F. Newns, On the representation of analytic functions by infinite series, Phil. Trans. Royal Soc. London (A) 245 (1953), 429-468.

8. A. E. Taylor, Introduction to Functional Analysis, John Wiley and Sons, New York, 1964.

Received November 7, 1969.

C. S. U. PERPIGNAN

Chemin De Villeneuve 



\section{PACIFIC JOURNAL OF MATHEMATICS}

\section{EDITORS}

\author{
H. SAMELSON \\ Stanford University \\ Stanford, California 94305 \\ Richard Pierce \\ University of Washington \\ Seattle, Washington 98105
}

\author{
J. DugundJI \\ Department of Mathematics \\ University of Southern California \\ Los Angeles, California 90007 \\ RICHARD ARENS \\ University of California \\ Los Angeles, California 9.0024
}

\section{ASSOCIATE EDITORS}

\begin{tabular}{|c|c|}
\hline E. F. BECKENBACH & K. YoshidA \\
\hline \multicolumn{2}{|c|}{ SUPPORTING INSTITUTIONS } \\
\hline UNIVERSITY OF BRITISH COLUMBIA & STANFORD UNIVERSITY \\
\hline CALIFORNIA INSTITUTE OF TECHNOLOGY & UNIVERSITY OF TOKYO \\
\hline UNIVERSITY OF CALIFORNIA & UNIVERSITY OF UTAH \\
\hline MONTANA STATE UNIVERSITY & WASHINGTON STATE UNIVERSITY \\
\hline UNIVERSITY OF NEVADA & UNIVERSITY OF WASHINGTON \\
\hline NEW MEXICO STATE UNIVERSITY & * \\
\hline OREGON STATE UNIVERSITY & AMERICAN MATHEMATICAL SOCIETY \\
\hline UNIVERSITY OF OREGON & CHEVRON RESEARCH CORPORATION \\
\hline OSAKA UNIVERSITY & TRW SYSTEMS \\
\hline UNIVERSITY OF SOUTHERN CALIFORNIA & NAVAL WEAPONS CENTER \\
\hline
\end{tabular}

The Supporting Institutions listed above contribute to the cost of publication of this Journal, but they are not owners or publishers and have no responsibility for its content or policies.

Mathematical papers intended for publication in the Pacific Journal of Mathematics should be in typed form or offset-reproduced, (not dittoed), double spaced with large margins. Underline Greek letters in red, German in green, and script in blue. The first paragraph or two must be capable of being used separately as a synopsis of the entire paper. The editorial "we" must not be used in the synopsis, and items of the bibliography should not be cited there unless absolutely necessary, in which case they must be identified by author and Journal, rather than by item number. Manuscripts, in duplicate if possible, may be sent to any one of the four editors. Please classify according to the scheme of Math. Rev. Index to Vol. 39. All other communications to the editors should be addressed to the managing editor, Richard Arens, University of California, Los Angeles, California, 90024.

50 reprints are provided free for each article; additional copies may be obtained at cost in multiples of 50 .

The Pacific Journal of Mathematics is published monthly. Effective with Volume 16 the price per volume (3 numbers) is $\$ 8.00$; single issues, $\$ 3.00$. Special price for current issues to individual faculty members of supporting institutions and to individual members of the American Mathematical Society: $\$ 4.00$ per volume; single issues $\$ 1.50$. Back numbers are available.

Subscriptions, orders for back numbers, and changes of address should be sent to Pacific Journal of Mathematics, 103 Highland Boulevard, Berkeley, California, 94708.

PUBLISHED BY PACIFIC JOURNAL OF MATHEMATICS, A NON-PROFIT CORPORATION

Printed at Kokusai Bunken Insatsusha (Internatıonal Academic Printing Co., Ltd.), 7-17, Fujimi 2-chome, Chiyoda-ku, Tokyo, Japan. 


\section{Pacific Journal of Mathematics}

\section{Vol. 35, No. $3 \quad$ November, 1970}

John D. Arrison and Michael Rich, On nearly commutative degree one algebras . . . 533

Bruce Alan Barnes, Algebras with minimal left ideals which are Hilbert spaces . . . . 537

Robert F. Brown, An elementary proof of the uniqueness of the fixed point index . . . 549

Ronn L. Carpenter, Principal ideals in F-algebras .................... 559

Chen Chung Chang and Yiannis (John) Nicolas Moschovakis, The Suslin-Kleene

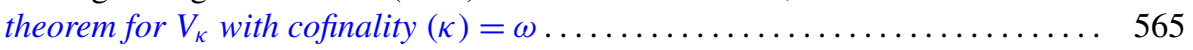

Theodore Seio Chihara, The derived set of the spectrum of a distribution

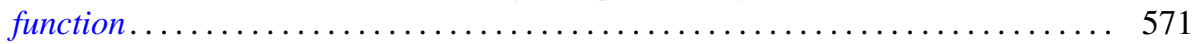

Tae Geun Cho, On the Choquet boundary for a nonclosed subspace of $C(S) \ldots \ldots \quad 575$

Richard Brian Darst, The Lebesgue decomposition, Radon-Nikodym derivative,

conditional expectation, and martingale convergence for lattices of sets .......

David E. Fields, Dimension theory in power series rings . . . . . . . . . . . .

Michael Lawrence Fredman, Congruence formulas obtained by counting

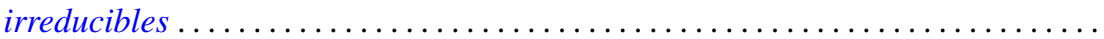

John Eric Gilbert, On the ideal structure of some algebras of analytic functions.....

G. Goss and Giovanni Viglino, Some topological properties weaker than

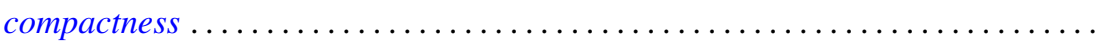

581

601

625

George Grätzer and J. Sichler, On the endomorphism semigroup (and category) of

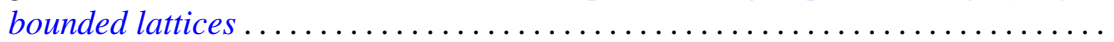

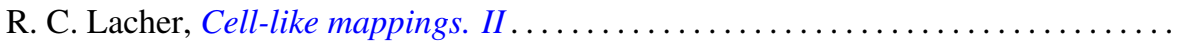

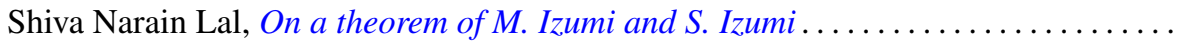

661

Howard Barrow Lambert, Differential mappings on a vector space ...............

Richard G. Levin and Takayuki Tamura, Notes on commutative power joined

semigroups.

Robert Edward Lewand and Kevin Mor McCrimmon, Macdonald's theorem for quadratic Jordan algebras.

J. A. Marti, On some types of completeness in topological vector spaces ....

Walter J. Meyer, Characterization of the Steiner point

717

Saad H. Mohamed, Rings whose homomorphic images are $q$-rings ...

727

Thomas V. O'Brien and William Lawrence Reddy, Each compact orientable surface

of positive genus admits an expansive homeomorphism ...

737

Robert James Plemmons and M. T. West, On the semigroup of binary relations...

743

Calvin R. Putnam, Unbounded inverses of hyponormal operator . .

755

William T. Reid, Some remarks on special disconjugacy criteria for differential

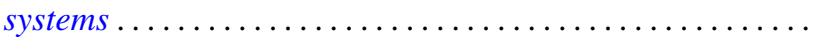

C. Ambrose Rogers, The convex generation of convex Borel sets in euclidean

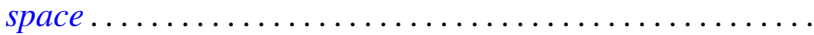

S. Saran, A general theorem for bilinear generating functions .

S. W. Smith, Cone relationships of biorthogonal systems ......

Wolmer Vasconcelos, On commutative endomorphism rings ....

795

Vernon Emil Zander, Products of finitely additive set functions from Orlicz

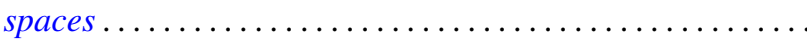

G. Sankaranarayanan and C. Suyambulingom, Correction to: "Some renewal

theorems concerning a sequence of correlated random variables" .

Joseph Zaks, Correction to: "Trivially extending decompositions of $E^{n}$ ”....... 805

Dong Hoon Lee, Correction to: "The adjoint group of Lie groups" ............ 805

James Edward Ward, Correction to: "Two-groups and Jordan algebras". 